\title{
Deep Brain Stimulation in Parkinson's Disease: Assessing Efficacy
}

\section{Fahad Somaa}

Occupational Therapy Department, Faculty of Medical Rehabilitation Science, King Abdulaziz University, Jeddah, Saudi Arabia
Correspondence: Fahad Somaa Occupational Therapy Department, Faculty of Medical Rehabilitation Science, King Abdulaziz University, Jeddah, Saudi Arabia

Tel +966500570777

Email fsomaa65@gmail.com

\begin{abstract}
Parkinson's disease (PD) has a chronic course. Currently, levodopa is the mainstay of treatment. However, long-term use of levodopa is interrupted by several side effects like dyskinesia and on-off fluctuations. Other pharmacological treatments also have adverse drug profiles and do not provide long-term relief, warranting the need for novel therapeutic approaches with a long-term efficacy profile in PD. Deep brain stimulation (DBS) is one such evolving technology with proven efficacy in advanced PD and promising results in early PD. DBS is mainly of two types, open- and closed-loop, of which open loop has been in routine use but closed loop is an innovative technology, only recently introduced for the treatment of PD. Apart from cost, DBS technology faces major challenges that hamper its integration into mainstream treatment paradigm of PD. Most of these challenges, including the cost can be overcome or considerably reduced by selecting the right DBS type, the right target for stimulation and the right patient selection. The review, therefore, assesses the efficacy of different parameters involved in selection of DBS as a treatment strategy such as patient characteristics, target characteristics, pros and cons of different DBS strategies, safety of DBS and stage of PD. The review may help clinicians to effectively use all these parameters to improve the outcomes of DBS.
\end{abstract}

Keywords: deep brain stimulation, Parkinson's disease, DBS in PD

\section{Introduction}

Parkinson's disease (PD), a chronic, progressive and debilitating neurodegenerative movement disorder, affects 1 to 2 per 1000 of the global population at any given point in time. ${ }^{1}$ The prevalence of PD increases with age affecting approximately $1-$ $3 \%$ of the global population aged 60 years and above. ${ }^{1-3}$

Currently levodopa is the mainstay of PD treatment. ${ }^{4}$ However, long-term use of levodopa is interrupted by several side effects like dyskinesia and on-off fluctuations. Other pharmacological treatments like dopamine agonists, catechol-O-methyl transferase (COMT) inhibitors, monoamine oxidase (MAO) inhibitors, amantadine, anticholinergic drugs, etc. also have adverse drug profiles and do not provide longterm relief from symptoms. ${ }^{4,5}$ Hence, patient's quality of life (QoL) progressively deteriorates. ${ }^{4}$ Therefore, novel therapeutic efficacious approaches that improve patient's QoL are required.

Deep brain stimulation (DBS) is an effective treatment for PD. DBS is mainly of two types: Conventional or open loop (cDBS) and closed loop (CL-DBS) or adaptive DBS (aDBS). cDBS is routinely used in PD treatment but CL-DBS is an innovative technology, only recently introduced for the treatment of PD. ${ }^{6}$ 
DBS has the potential to reduce motor and non-motor PD symptoms by $60-80 \%$, with sustained reduction in medication use by $44 \%$ after 8 to 15 years of surgery. ${ }^{7,8}$ Efficacy is achieved by modulating neural activity through a "brain pacemaker" implanted surgically for electrical stimulation to key brain structures, known as DBS targets. ${ }^{9}$ Electrical stimulation can be modulated by changing frequency, pulse width and intensity to induce the desired clinical outcomes in PD. ${ }^{9}$ Moreover, unlike surgical ablation, DBS can be performed bilaterally without major adverse effects. ${ }^{9-12}$ High-frequency stimulation of brain targets has proven to be efficacious in the long run. ${ }^{9}$ Also, patient satisfaction with the treatment and symptom control and ability to carry out activities of daily living (ADL) persists for a long time after DBS. ${ }^{13}$ The efficacy and reversible nature of DBS along with the potential to significantly reduce the burden of drug therapy, has carved an important place for DBS in the long-term treatment of PD. ${ }^{9}$

However, despite its advantages, DBS is not a widely accepted technique; approximately only $2 \%$ of patients with PD undergo DBS. In many parts of the world, patients with PD have limited access to DBS; the treatment is costly and patients fear its invasive nature. ${ }^{9}$ To improve patient outcomes in $\mathrm{PD}$, it is very important to access the benefits of different DBS targets, devices and strategies and understand the patient characteristics that will improve DBS outcomes.

In this review, we elaborate on the efficacy of DBS in PD by understanding the role of effective patient, target and strategy selection. The review also covers upcoming technologies and their efficacy and ways to measure DBS efficacy. We also provide an overview of DBS efficacy in early versus advanced PD.

\section{Literature Search Strategy}

General literature search: a Google Scholar and PUBMED search was carried out from the year 2000 to 2020 by combining the following search terms using Boolean operators "AND/OR": "efficacy", "deep brain stimulation", "DBS", "Parkinson's disease", "DBS targets", "Subthalamic nucleus (STN)", "Internal globus pallidus (GPi), "Ventral intermediate nucleus (Vim)", "Pedunculopontine nucleus (PPN)", and "Posterior subthalamic area (PSA)". Studies demonstrating the efficacy of DBS in PD were included in the review. Only English language publications were considered.

\section{Efficacy Measures}

Several scales are used to assess the efficacy of DBS treatment in PD. Historically, scales like the Webster, Columbia University Rating Scale, and Parkinson's disease Impairment Scale had been developed to assess motor symptoms. ${ }^{14}$ The Schwab and England and Northwestern University Disability Scale were developed to assess disability component. The Unified Parkinson's Disease Rating Scale (UPDRS) and New York University Scale were developed to assess both motor and disability components. $^{14}$

However, of these, UPDRS (Table 1) became the most widely accepted tool. The UPDRS has four subscales: I to IV. ${ }^{15-18}$ The UPDRS scale did not elaborate much on the non-motor symptoms and relied heavily on the patient/

Table I Unified Parkinson's Disease Rating Scale (UPDRS) and Movement Disorders Society Revision of UPDRS (MDS-UPDRS)

\begin{tabular}{|c|c|c|c|}
\hline Subscale & $\begin{array}{l}\text { Assessment Made } \\
\text { (UPDRS) }^{15-18}\end{array}$ & $\begin{array}{l}\text { Assessment Made } \\
\text { MDS-UPDRS }\end{array}$ & Method of Assessing \\
\hline I & $\begin{array}{l}\text { Mentation, behavior, } \\
\text { and mood }\end{array}$ & $\begin{array}{l}\text { Non-motor Experiences } \\
\text { of Daily Living }\end{array}$ & $\begin{array}{l}\text { Data elicited from patient or caregiver; Reliability depends on patient/caregiver } \\
\text { reporting and examiner's ability to elicit response. }\end{array}$ \\
\hline II & $\begin{array}{l}\text { Activities of daily } \\
\text { living }\end{array}$ & $\begin{array}{l}\text { Motor Experiences of } \\
\text { Daily Living }\end{array}$ & $\begin{array}{l}\text { Data elicited from patient or caregiver; Training tapes are available to improve } \\
\text { reliability of measures }\end{array}$ \\
\hline III & $\begin{array}{l}\text { Clinician rated motor } \\
\text { manifestations }\end{array}$ & Motor Examination & Examination based; Training tapes are available to improve reliability of measures \\
\hline IV & $\begin{array}{l}\text { Complications of } \\
\text { therapy }\end{array}$ & Motor Complications & $\begin{array}{l}\text { Data elicited from patient or caregiver; Reliability depends on patient/caregiver } \\
\text { reporting and examiner's ability to elicit response. }\end{array}$ \\
\hline $\begin{array}{l}\text { Final } \\
\text { scoring }\end{array}$ & \multicolumn{2}{|c|}{$\begin{array}{l}\text { Five response options: } 0=\text { normal, } \mathrm{I}=\text { slight, } 2= \\
\text { mild, } 3=\text { moderate, and } 4=\text { severe }\end{array}$} & $\begin{array}{l}\text { UPDRS: not an interval scale, not quantifiable; a score of } 4 \text { is not twice as severe } \\
\text { as score of } 2 \text {. } \\
\text { MDS-UPDRS: scores have uniform anchors }\end{array}$ \\
\hline
\end{tabular}


caregiver's ability to report symptoms. Therefore the Movement Disorders Society revision of the UPDRS (MDS-UPDRS) ${ }^{19}$ scale is currently used to assess improvement in DBS treatment. ${ }^{20}$

New efficacy measures are being explored to assess the efficacy of DBS. Dong et al (2020) explored whether Executive Control Network (ECN) could be used to assess the efficacy of DBS. ${ }^{21}$ They found no difference in the functional connectivity (FC) of the ECN in PD before and after DBS. However FC to ECN differed between patients with PD and controls. The researchers concluded that ECN could be used to diagnose PD but not assess the efficacy of DBS. $^{21}$

\section{Patient Selection for Improved Efficacy}

The efficacy of DBS depends on the expertise of the neurosurgery team ${ }^{9}$ and on patient characteristics. ${ }^{22,23}$ The "Core Assessment Program for Neurosurgical Interventions and Transplantation in Parkinson's Disease" (CAPSIT-PD) recommends that surgical intervention in PD should be considered in patients with disease duration of at least 5-years. ${ }^{22}$ However, patients who are adequately controlled by medical management are not candidates for DBS. $^{23}$

Patients should be critically chosen based on their symptoms, age and cognition status as the right patient selection increases the efficacy of DBS. ${ }^{9}$ More than $30 \%$ of the DBS failures are because of improper patient selection. ${ }^{23}$ Patients with non-motor symptoms (poor cognition, dysautonomia, postural instability, dysarthria, or dysphagia) not responsive to medication, also do not respond to DBS too.

The following patients on optimal drug therapy (ODT) are more likely to have good and sustained response to DBS if they have the following characteristics: ${ }^{9,22,24}$ idiopathic $\mathrm{PD} /$ advanced $\mathrm{PD}$; robust response to levodopa (>30\% improvement in UPDRS III); ineffective management of symptoms with levodopa can increase risk of DBS rejection by $50 \%$; experiencing complications to medical therapy (dyskinesias or motor fluctuations: significant off and on time); lack of significant psychiatric and/or mood symptoms; no history of dementia or depression; and $<70$ years old.

Unrealistic patient expectations should be addressed before DBS as these can reduce patient satisfaction and has shown to result in patients rejecting the effect of DBS in $38 \%$ of cases. $^{24}$ Adding unrealistic expectations as a disqualifying criteria for patient selection for DBS can significantly improve patient selection for $\mathrm{DBS}^{24}$

\section{Effective Targets}

Apart from patient selection, target selection is very important for effective and desired DBS outcome. Various DBS targets in the brain, STN, GPi, Vim, PPN, and PSA, have been effectively used and assessed to show improvement on the MDS-UPDRS scale (Table 2). Of these, STN DBS and STN GPi are the most commonly used and studied targets. ${ }^{25,26}$ There is no consensus on the best target for DBS in PD. ${ }^{26}$ Hence, DBS targets have to be chosen cautiously after assessing patient symptoms, age and cognitive status and role of the targets in improving symptoms and cognition (Table 2)., ${ }^{9,22}$

\section{Comparing STN DBS with GPi DBS}

Sustained benefits of DBS of STN and GPi have been reported on motor function, motor fluctuations, dyskinesia and QoL. ${ }^{27-30}$ Several studies have shown that STN DBS can reduce levodopa equivalent daily dose (LED) by $48 \%$ to $>50 \%, 1$ to 4 years post-surgery ${ }^{31,32}$ STN DBS is more effective in reducing LED than GPi DBS. ${ }^{33,34}$ Thomsen et al (2020) showed a reduction in medication use by $55 \%$ and $44 \%$ after 1 year and 8 to 15 years, respectively of STN DBS. ${ }^{8}$

Though both targets reduce levodopa induced dyskinesia (LID), GPi DBS is more effective in reducing LID than STN DBS (47-88\% vs 20-83\%, respectively). ${ }^{35}$ Post DBS increase in levodopa dose results in higher rates of dyskinesia with STN DBS than GPi DBS. ${ }^{27,36-39}$

The two targets are comparable in improving rigidity and bradykinesia. A network meta-analysis of 16 studies looking at UPDRS improvement showed similar efficacy of GPi DBS ( $-3.9 ; 95 \%$ confidence interval [CI] -7.0 to $-0.96)$ and STN DBS $(-3.1 ; 95 \%-5.9$ to -0.38$)$ in improving UPDRS scores in the "on medication" phase. ${ }^{26}$ Both the targets show similar effect on mood, ${ }^{40}$ but GPi DBS is associated with lesser mood, cognition and behavior abnormalities than STN DBS. ${ }^{25}$ A meta-analysis showed that STN DBS is associated with decreases in executive function, memory, attention, psychomotor speed and semantic and phonemic verbal fluency; while. GPi DBS showed small deficits only in verbal fluency and attention. $^{41}$ Though, patients report better QoL after both GPi DBS and STN DBS, the QoL after GPi DBS was significantly better $(\mathrm{P}=0.03)$ than that post STN DBS on 
Table 2 DBS Benefits on Different Targets

\begin{tabular}{|c|c|c|}
\hline Target & Effect & $\begin{array}{l}\text { Benefit of DBS (Conventional DBS Unless } \\
\text { Specified) }\end{array}$ \\
\hline \multicolumn{3}{|l|}{ Established targets } \\
\hline $\begin{array}{l}\text { Subthalamic nucleus (STN) and local fiber } \\
\text { pathways }\end{array}$ & $\begin{array}{l}\text { Suppress cardinal PD symptoms like } \\
\text { bradykinesia, rigidity and tremor }{ }^{9}\end{array}$ & 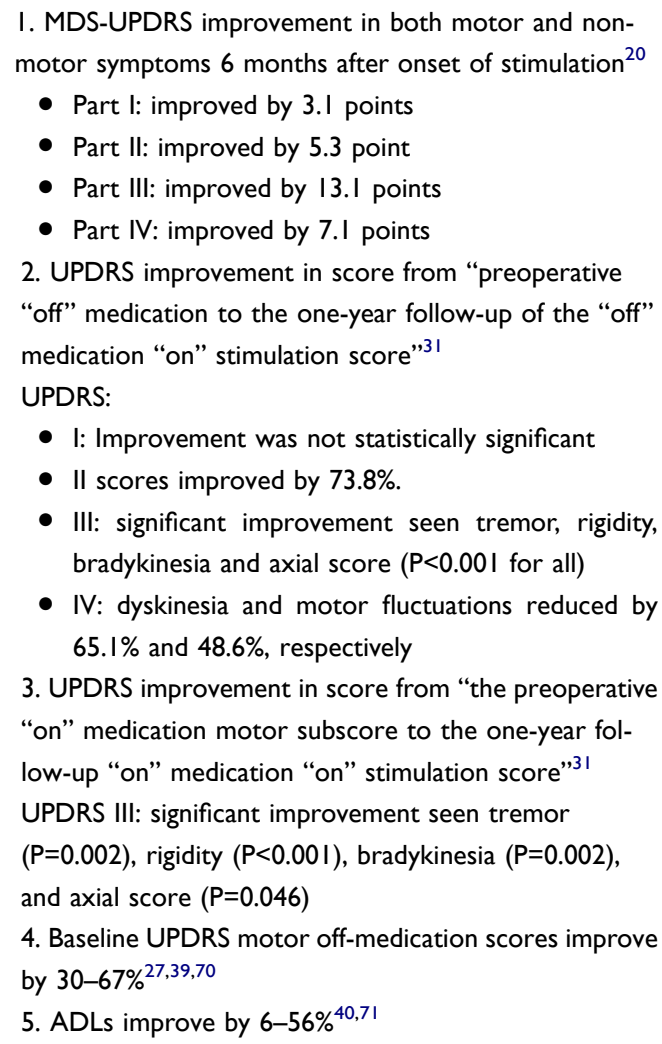 \\
\hline Internal globus pallidus (GPi) & $\begin{array}{l}\text { Strong antidyskinesia effect; Suppress } \\
\text { cardinal PD symptoms like } \\
\text { bradykinesia, rigidity and tremor }{ }^{25}\end{array}$ & $\begin{array}{l}\text { I. Baseline UPDRS motor off-medication scores improve } \\
\text { by } 27-54 \%^{70,72,73} \\
\text { 2. ADLs improve by } 30-39 \%^{40,72,73}\end{array}$ \\
\hline \multicolumn{3}{|l|}{ Newer targets } \\
\hline \multicolumn{3}{|c|}{ Ventrolateral thalamus: Reduces tremor severity; relatively ineffective in improving bradykinesia and rigidity ${ }^{9}$} \\
\hline Ventral intermediate nucleus (Vim) & $\begin{array}{l}\text { Mostly effective in controlling } \mathrm{ET}^{74,75} \\
\text { or in patients with } \mathrm{PD} \text { and } \mathrm{ET}^{26,76}\end{array}$ & $\begin{array}{l}\text { I. According to a network-meta-analysis, Vim DBS shows } \\
\text { better improvement in UPDRS scores than GPi DBS and } \\
\text { STN DBS in off medication phase and therefore can be } \\
\text { used in tremor dominant PD } \\
\text { 2. The beneficial effect of Vim DBS has been seen even } \\
10 \text { years post procedure }\end{array}$ \\
\hline $\begin{array}{l}\text { Pedunculopontine nucleus (PPN) } \\
\text { Typically low stimulation frequencies are } \\
\text { employed ( } 20-80 \text { Hertz) and closed-loop } \\
\text { DBS strategies are employed. }\end{array}$ & $\begin{array}{l}\text { Effective in PD patients with } \\
\text { predominant postural instability and } \\
\text { gait difficulty (PIGD) } \\
\text { Usually used with simultaneous STN } \\
\text { DBS) as its efficacy as a lone target is } \\
\text { debatable. }^{78}\end{array}$ & $\begin{array}{l}\text { I. Bilateral PPN DBS alone }{ }^{79} \\
\text { - Total UPDRS improved by } 53 \% \\
\text { - UPDRS part III (motor sub score) improved by } 57 \% \\
\text { - Levodopa dose reduction by } 32.5 \% \\
\text { 2. Dual PPN DBS and STN DBS } 80 \\
\text { UPDRS III reduction in off medication phase: } 56 \% \text { STN } \\
\text { plus PPN DBS vs } 54 \% \text { STN DBS and } 33 \% \text { PPN DBS } \\
\text { 3. Dual PPN DBS and STN DBS improves spinal excit- } \\
\text { ability in PD. }\end{array}$ \\
\hline
\end{tabular}

(Continued) 
Table 2 (Continued).

\begin{tabular}{|c|c|c|}
\hline Target & Effect & $\begin{array}{l}\text { Benefit of DBS (Conventional DBS Unless } \\
\text { Specified) }\end{array}$ \\
\hline Posterior subthalamic area (PSA) & Effective in PD tremor 82 & $\begin{array}{l}\text { Two years after surgery } \\
\text { - Tremor improved by } 78.3 \% \\
\text { - Rigidity by } 92.7 \% \\
\text { - Akinesia by } 65.7 \% \\
\text { - Gait, posture and handwriting also showed } \\
\text { improvement }\end{array}$ \\
\hline Dual STN and caudal zona incerta (cZl) & $\begin{array}{l}\text { cZl associated with better motor } \\
\text { improvement than BMT, especially } \\
\text { tremor }^{46}\end{array}$ & $\begin{array}{l}\text { Improvement in mean UPDRS part III score in patients } \\
\text { with idiopathic PD was } 55 \pm 9 \%(95 \% \mathrm{Cl}) \text {; improvement } \\
\text { in subscores for rigidity, bradykinesia, tremor and axial } \\
\text { features. }{ }^{47}\end{array}$ \\
\hline
\end{tabular}

Abbreviations: ADL, activities of daily living; BMT, best medical treatment; Cl, confidence interval; ET, essential tremor; PD, Parkinson's disease; UPDRS, Unified Parkinson Disease Rating Scale.

various fronts such as mobility, ADLs, cognition, discomfort, stigma, and emotional well-being. ${ }^{40}$

The overall side effect profile of both targets is similar, but speech related adverse effects, dysphagia and gait disturbances are more common in STN DBS than GPi DBS. ${ }^{42-45}$

As seen in this comparative review section, both STN DBS and GPi DBS are efficacious and safe targets in PD. Both STN DBS and GPi DBS have similar benefits, but a particular benefit may be more pronounced by targeting one of them. Hence, it is difficult to conclude which is a better target for DBS. Therefore, the choice between these two targets should be carefully based on the outcome desired.

\section{New and Emerging Targets}

Since, there is no consensus on the best target for DBS in PD and because no target is able to effectively manage all the patient's symptoms and QoL over a prolonged period, newer targets and dual target stimulation is being investigated to improve PD outcomes in patients with refractory motor and non-motor symptoms. ${ }^{11}$ Stimulation of caudal zona incerta (cZI) is associated with better motor control than best medical treatment (BMT). ${ }^{46}$ Dual stimulation of STN and cZI has been tried with better results that targeting individual regions. ${ }^{47}$ Also, Vim, PPN, and PSA are the newer targets found to be effective in different PD patient populations (Table 2). ${ }^{11}$

\section{Efficacy of Different DBS Strategies and Technologies}

Efficacy of DBS is also dependent on the strategy and technology used such as cDBS, CL-DBS/aBDS, and the electrode used as these modulate the volume of tissue activated (VTA). The VTA in cDBS, CL-DBS/aBDS correlates directly with the accuracy and efficacy of the target stimulated. ${ }^{9}$ The electrode used for DBS should be designed such that it provides a flexible interface to facilitate the application to different targets and compensate for morphological and surgical variance. ${ }^{9}$ VTA around an optimal electrode depends on the number of contacts required for stimulation, properties of surrounding tissue and simulation parameters (frequency, amplitude and width used). ${ }^{9}$

\section{Open Loop DBS or Conventional DBS}

cDBS is the most commonly used strategy in PD with a known efficacy on different targets (Table 2). ${ }^{6}$ However, since no sensor is used for feedback control of the electrical stimulation, cDBS is associated with several problems. Programming in cDBS is intricate and time consuming, and therefore needs very skilled staff. ${ }^{6}$ cDBS needs frequent reprogramming, which adds to the treatment cost of an already costly procedure. Further continuous stimulation is associated with shorter battery life, requiring frequent surgical procedures to change battery. ${ }^{6}$ Hence, other DBS technologies are continuously being assessed to improve patient experience and reduce treatment cost.

\section{Closed-Loop DBS or Adaptive DBS Strategies}

CL-DBS/aDBS strategies use the same electrode for sensing and stimulating and therefore minimal surgical 
instrumentation is required. ${ }^{9}$ In these strategies only the required stimulation is provided for a certain time window. Feedback control is provided by a neurophysiological biomarker ( $\beta$ oscillatory activity of $12-30 \mathrm{~Hz}$ or pulse amplitude) guided automatic adjustment of the stimulation. ${ }^{6,9}$ This is found to be more energy efficient (unwanted direct stimulation of nearby fiber tracts is controlled), more effective in improving motor symptoms and less likely to cause speech impairment/dysarthria than cDBS. ${ }^{48,49}$ About half the aDBS simulations delivered in the "off medication" state show efficacy; the efficacy is still higher with stimulations delivered in "on medication" state. aDBS may also be useful for patients experiencing brittle dyskinesia on STN DBS. ${ }^{49}$ Corticopallidal CL-DBS yields greater reduction of oscillatory neuronal discharge and better alleviation of Parkinsonian akinesia. ${ }^{50}$
The efficacy of aDBS is, however, affected by external environmental conditions that interfere with the detection of the biomarker. These include temperature variations, functional disruptions in device, interactions with magnetic field or electric currents. ${ }^{6}$ This problem can be overcome by using a device with multiple feedback signals. ${ }^{51}$ Both cDBS and CL-DBS continues to face many challenges for successful integration into the treatment paradigm of PD (Figure 1). ${ }^{6}$ Additionally these are bulkier devices than cDBS. Various micro-chip technologies are being used to constantly improve the efficacy and size of CL-DBS, but are mostly in the experimental stage. ${ }^{52}$

\section{Efficacy of Different Frequency DBS}

Traditionally high frequency DBS is used for electrical stimulation of the targets. However, high frequency DBS can have some adverse effects. High frequency DBS

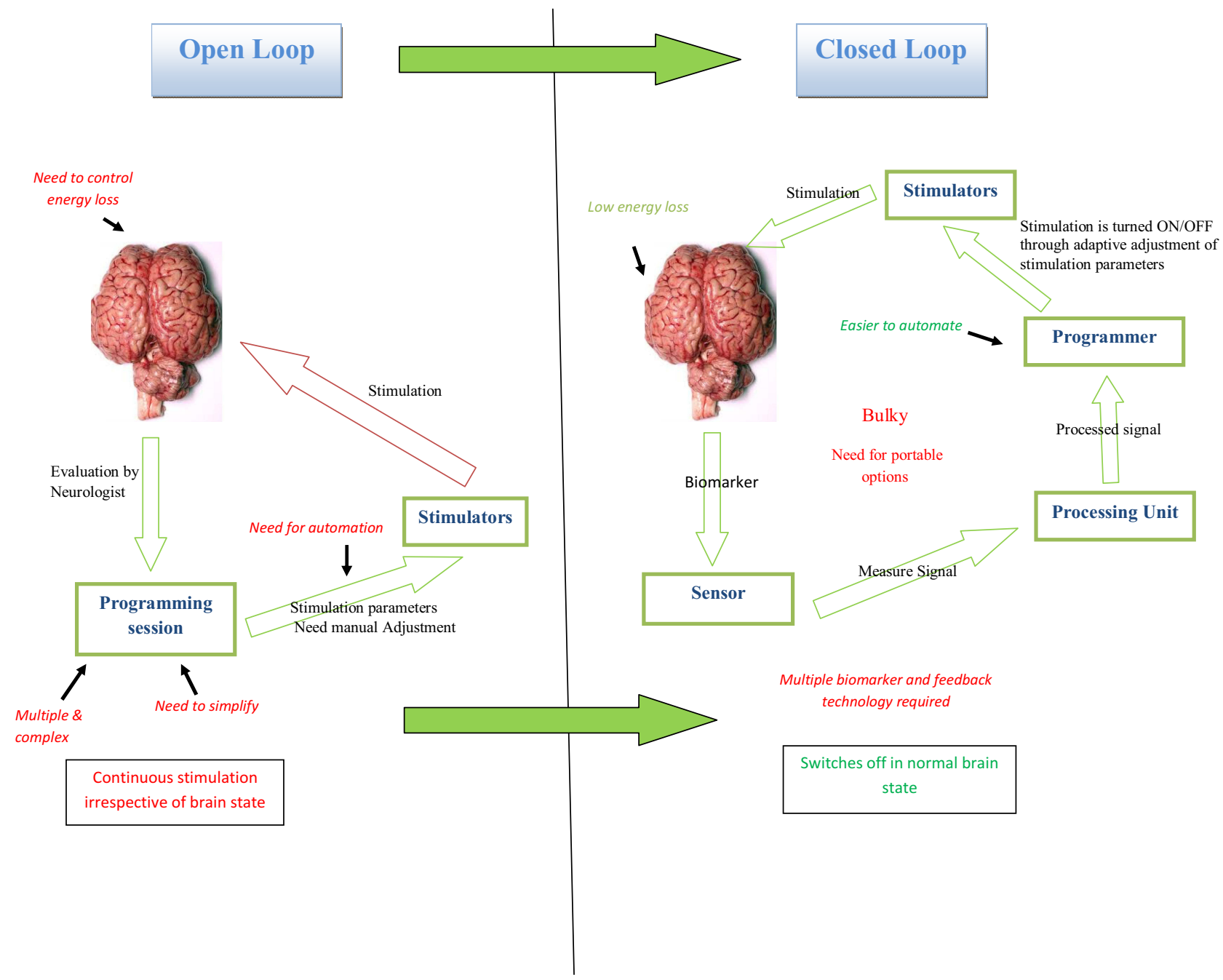

Figure I Open versus closed-loop DBS. 
administered during a patient's decision making process can impair patient behavior. ${ }^{53,54}$ A study showed that an adverse effect on patient's gait could be improved by alternating the simulation patterns between hemispheres based on the patient's walking pattern. ${ }^{55}$ High frequency simulation can affect a patient's sleep quality, either positively or negatively, depending upon the DBS target used. ${ }^{55,56}$ Therefore other frequency DBS are also being assessed for optimal stimulation patterns based on sleep, walking, gait and decision making. ${ }^{57-59}$ However, results have been controversial and do not show a conclusive benefit of other frequencies (including low frequency) over high frequency DBS. ${ }^{57-59}$

DBS optimized according to the anatomy and physiology of the brain target is likely to be more effective than high frequency DBS in the long run as it will limit the amount of energy delivered, reduce side effects and induce long plastic changes. ${ }^{9}$

\section{Efficacy of Segmented versus Conventional Electrodes}

VTA can be modified according to requirement by using segmented electrodes instead of cylindrical ones, as this allows field steering and independent control over electrode contacts. ${ }^{9,60,61}$ The segmented electrodes have a better design, lesser side effects, and cause lesser activation of surrounding tissue than cylindrical ones; hence they provide a larger therapeutic window and give the time to clinicians to modify side-effect thresholds. ${ }^{9,60,61}$

\section{Efficacy of Local (Awake) versus General Anesthesia (Sleep) Techniques}

A meta-analysis of 145 studies $(n=2563)$ of DBS in PD (16 on general anesthesia, GA/sleep; rest local anesthesia, LA/awake) showed that the mean target error was not significantly different between LA and GA; however the mean number of DBS lead passes were significantly less with GA as compared to LA $(\mathrm{P}=0.006) .{ }^{62}$ Post DBS complications (especially infections and intracerebral hemorrhage) were significantly lower with GA (P < 0.001). The two techniques did not differ significantly in UPDRS II scores "off medication", UPDRS III scores "off" and "on medication" or LED. UPDRS IV "off medication" score decreased more significantly in awake DBS versus sleep DBS cohorts $(78.4 \%$ vs $59.7 \%, \mathrm{P}=0.022){ }^{62}$ Hence, most DBS procedures should ideally be carried out under LA due to the lower side effect profile.

\section{Effectiveness of DBS in Advanced versus Early PD}

The efficacy of DBS in advanced PD is widely reported and assessed using MDS-UPDRS I-IV. Stimulation of different targets provides different improvements in symptoms; however, most improve motor symptoms and activities of daily living (ADL) in advanced PD. A metaanalysis of 13 randomized controlled trials found significant improvement in PD symptoms after DBS. However, GPi DBS and STN DBS resulted in similar improvement in motor scores or ADL at 36 months. STN DBS significantly reduced medication use as compared to GPi DBS (P $=0.002)$. GPi DBS, on the other hand, significantly improved Beck Depression Inventory scores as compared to STN DBS $(\mathrm{P}=0.001)$.

However, recently efficacy of DBS in early PD is showing promising results. A meta-analysis of eight RCTs ( $=1189$ ), of which two recruited early PD patients showed that the UPDRS, Parkinson's disease questionnaire (PDQ)-39, and LED scores improved significantly with DBS as compared to BMT $(\mathrm{P}<0.00001) .{ }^{4}$ Patients with early PD had a significantly greater reduction of LED than those with advanced PD ( $\mathrm{P}<0.00001)$. No other differences were found in efficacy outcomes between early and advanced PD. ${ }^{4}$

A very recent prospective randomized trial in early PD patients followed for 5-years showed that STN DBS given along with ODT significantly reduced LED $(\mathrm{P}=0.04)$, polypharmacy $(\mathrm{P}=0.01)$ and disease progression (especially rest tremor) $(\mathrm{P}<0.001)$ compared to only on ODT. ${ }^{63}$ Patients on DBS + ODT had a safety profile similar to patients on only ODT.

However, despite its various benefits, currently, conventionally DBS is not used in early PD.

\section{Minimizing DBS Side Effects for Improved Efficacy}

Efficacy of DBS will be higher if the safety profile is manageable and the procedure is acceptable to the patients. Since it is a surgical procedure, usual surgery associated complications such as hemorrhage, infection, and skin erosion are seen. ${ }^{64}$ Other than these, hardwarerelated complications such as electrode fracture and stimulator failure have been reported. ${ }^{65}$

However, the most annoying, common (seen in up to $50 \%$ patients) and important postoperative complication of DBS is the side effects caused by electrical stimulation of 
the surrounding brain tissue; these are largely driven by the DBS target and anatomy and functionality of the surrounding brain tissue. ${ }^{66}$ However, these side effects are easily manageable in most cases. ${ }^{66}$ Emerging technologies such as segmented electrodes and CL-DBS aim to minimize these side effects. ${ }^{9}$

\section{Strengths and Limitations}

Like most narrative reviews, this review also has a publication selection bias. DBS has evolved more slowly than medical therapy and therefore literature covered in this review could not be distributed equally over the time period covered.

However, the review has tried to assess factors driving the efficacy of DBS by covering the different parameters involved in the selection of DBS as a treatment strategy such as patient characteristics, target characteristics, pros and cons of different DBS strategies, safety of DBS and stage of PD. If clinicians can effectively use all these parameters to improve the outcomes of DBS, it will help in the better integration of this effective non-pharmacology based therapy into the treatment paradigm of PD.

\section{Summary and Future Prospects}

The review shows that DBS is an effective and evolving treatment strategy in PD. However, despite its benefits, it is not widely accepted or widely available due to cost and need for highly skilled staff to manage the programming and stimulation. Additionally, there are challenges of repeat surgeries and short battery life. DBS efficacy, accuracy and acceptability can be improved by overcoming these challenges.

Therefore, upcoming DBS technologies would need to focus on reducing electrode contact size and stimulation number, and move from an invasive to a non-invasive approach. ${ }^{9,67}$ Newer technologies like current steering can reduce the VTA. ${ }^{67}$ The VANTAGE study shows that multiple-source axially asymmetric directional DBS using segmented electrodes can be more efficacious than cDBS technologies without steering. ${ }^{60,61}$ Newer biomarkers and electrode designs like rhythmic neural activity and evoked potentials for segmented electrodes can reduce the programming time. ${ }^{9}$ Automated support tools to determine the optimal stimulation parameters can increase the penetration of technology in areas where highly skilled staff are not available. ${ }^{9}$

Today updated software using imaging technologies allows patient specific reconstruction of DBS leads with fully automated tools such as PaCER ${ }^{67}$ Recently, a smartphone based wearable and wireless accelerometer and gyroscope platform was successfully used for quantified feedback for optimal configuration of CL-DBS tuning parameters. ${ }^{68}$

As highlighted in the review, DBS holds a promising place in early PD as well. Further research is required to understand patient and target selection for optimal DBS response in early PD. As newer technologies are being tried, it may be possible in the near future to move towards an automated DBS procedure that is less expensive and equally or more efficacious in both early and advanced PD.

\section{Ethics Compliance}

Not required. It's a narrative review.

\section{Funding}

There is no funding to report.

\section{Disclosure}

The author reported no conflicts of interest for this work.

\section{References}

1. Tysnes O-B, Storstein A. Epidemiology of Parkinson's disease. $J$ Neural Transm. 2017;124(8):901-905. doi:10.1007/s00702-017$1686-\mathrm{y}$

2. Ball N, Teo W-P, Chandra S, Chapman J. Parkinson's Disease and the Environment. Front Neurol. 2019;10:10. doi:10.3389/ fneur.2019.00218

3. Balestrino R, Schapira AHV. Parkinson disease. Eur J Neurol. 2020;27(1):27-42. doi:10.1111/ene.14108

4. Bratsos S, Karponis D, Saleh SN. Efficacy and Safety of Deep Brain Stimulation in the Treatment of Parkinson's Disease: a Systematic Review and Meta-analysis of Randomized Controlled Trials. Cureus. 2018;10:10. doi:10.7759/cureus.3474

5. Pradahan M, Srivastava R. Etiology. Epidemiology, Diagnosis and Current Therapeutic Protocols for Parkinson's Disease (PD): an Overview. Int $J$ Contemporary Med Surg Radiol. 2020;5. doi:10.21276/ijcmsr.2020.5.1.41

6. Parastarfeizabadi M, Kouzani AZ. Advances in closed-loop deep brain stimulation devices. J Neuroeng Rehabil. 2017;14(1):79. doi:10.1186/s12984-017-0295-1

7. deSouza R-M, Moro E, Lang AE, Schapira AHV. Timing of deep brain stimulation in Parkinson disease: a need for reappraisal? Ann Neurol. 2013;73(5):565-575. doi:10.1002/ana.23890

8. Thomsen BLC, Jensen SR, Clausen A, Karlsborg M, Jespersen B. Deep Brain Stimulation in Parkinson's Disease: still Effective After More Than 8 Years. Movement Dis Clin Pract. 2020;7(7):788-796. doi:10.1002/mdc3.13040

9. Cagnan H, Denison T, McIntyre C, Brown P. Emerging technologies for improved deep brain stimulation. Nat Biotechnol. 2019;37 (9):1024-1033. doi:10.1038/s41587-019-0244-6

10. Rodriguez-Oroz MC, Obeso JA, Lang AE, et al. Bilateral deep brain stimulation in Parkinson's disease: a multicentre study with 4 years follow-up. Brain. 2005;128(10):2240-2249. doi:10.1093/brain/ awh571 
11. Anderson D, Beecher G, Ba F. Deep Brain Stimulation in Parkinson's Disease: new and Emerging Targets for Refractory Motor and Nonmotor Symptoms. Parkinson's Disease. 2017;2017. doi:10.1155/ 2017/5124328

12. Chao Y, Gang L, Na ZL, Ming WY, Zhong WS, Mian WS. Surgical Management of Parkinson's Disease: update and Review. Interv Neuroradiol. 2007;13(4):359-368. doi:10.1177/ 159101990701300407

13. Hitti FL, Ramayya AG, McShane BJ, Yang AI, Vaughan KA, Baltuch $\mathrm{GH}$. Long-term outcomes following deep brain stimulation for Parkinson's disease. $J$ Neurosurg. 2019;132(1):205-210. doi:10.3171/2018.8.JNS182081

14. Ramaker C, Marinus J, Stiggelbout AM, Van Hilten BJ. Systematic evaluation of rating scales for impairment and disability in Parkinson's disease. Mov Disord. 2002;17(5):867-876. doi:10.1002/ mds. 10248

15. Goetz CG, LeWitt PA, Weidenman M. Standardized training tools for the UPDRS activities of daily living scale: newly available teaching program. Mov Disord. 2003;18(12):1455-1458. doi:10.1002/ mds. 10591

16. Goetz CG, Stebbins GT, Chmura TA, Fahn S, Klawans HL, Marsden CD. Teaching tape for the motor section of the unified Parkinson's disease rating scale. Mov Disord. 1995;10(3):263-266. doi:10.1002/ mds. 870100305

17. Goetz CG, Stebbins GT. Assuring interrater reliability for the UPDRS motor section: utility of the UPDRS teaching tape. Mov Disord. 2004;19(12):1453-1456. doi:10.1002/mds.20220

18. Louis ED, Lynch T, Marder K, Fahn S. Reliability of patient completion of the historical section of the Unified Parkinson's Disease Rating Scale. Mov Disord. 1996;11(2):185-192. doi:10.1002/ mds. 870110212

19. Goetz CG, Fahn S, Martinez-Martin P, et al. Movement Disorder Society-sponsored revision of the Unified Parkinson's Disease Rating Scale (MDS-UPDRS): process, format, and clinimetric testing plan. Mov Disord. 2007;22(1):41-47. doi:10.1002/mds.21198

20. Chou KL, Taylor JL, Patil PG. The MDS-UPDRS tracks motor and non-motor improvement due to subthalamic nucleus deep brain stimulation in Parkinson disease. Parkinsonism Relat Disord. 2013;19:11. doi:10.1016/j.parkreldis.2013.06.010

21. Dong W, Qiu C, Jiang X, et al. Can the Executive Control Network be Used to Diagnose Parkinson's Disease and as an Efficacy Indicator of Deep Brain Stimulation? Parkinson's Disease. 2020;2020. doi:10.1155/2020/6348102

22. Dallapiazza RF, Vloo PD, Fomenko A, et al. Considerations for Patient and Target Selection in Deep Brain Stimulation Surgery for Parkinson's Disease. Codon Publications; 2018. doi:10.15586/codonpublications.parkinsonsdisease.2018.ch8

23. Pouratian N, Thakkar S, Kim W, Bronstein JM. Deep brain stimulation for the treatment of Parkinson's disease: efficacy and safety. Degener Neurol Neuromuscul Dis. 2012;2:107-117. doi:10.2147/ DNND.S25750

24. Geraedts VJ, Kuijf ML, van Hilten JJ, Marinus J, Oosterloo M, Contarino MF. Selecting candidates for Deep Brain Stimulation in Parkinson's disease: the role of patients' expectations. Parkinsonism Relat Disord. 2019;66:207-211. doi:10.1016/j.parkreldis.2019.07.011

25. Mirza S, Yazdani U, Dewey III R, et al. Comparison of Globus Pallidus Interna and Subthalamic Nucleus in Deep Brain Stimulation for Parkinson Disease: an Institutional Experience and Review. Parkinson's Disease. 2017;2017. doi:10.1155/2017/3410820

26. Mao Z, Ling Z, Pan L, et al. Comparison of Efficacy of Deep Brain Stimulation of Different Targets in Parkinson's Disease: a Network Meta-Analysis. Front Aging Neurosci. 2019:11. doi:10.3389/ fnagi.2019.00023

27. Weaver FM, Follett KA, Stern M, et al. Randomized trial of deep brain stimulation for Parkinson disease. Neurology. 2012;79(1):5565. doi:10.1212/WNL.0b013e31825dcdc1
28. Odekerken VJJ, Boel JA, Schmand BA, et al. GPi vs STN deep brain stimulation for Parkinson disease: three-year follow-up. Neurology. 2016;86(8):755-761. doi:10.1212/WNL.0000000000002401

29. Rughani A, Schwalb JM, Sidiropoulos C, et al. Congress of Neurological Surgeons Systematic Review and Evidence-Based Guideline on Subthalamic Nucleus and Globus Pallidus Internus Deep Brain Stimulation for the Treatment of Patients With Parkinson's Disease: executive Summary. Neurosurgery. 2018;82 (6):753-756. doi:10.1093/neuros/nyy037

30. Cernera S, Eisinger RS, Wong JK, et al. Long-term Parkinson's disease quality of life after staged DBS: STN vs GPi and first vs second lead. NPJ Parkinsons Dis. 2020;6:6. doi:10.1038/s41531-020-0115-3

31. Rabie A, Verhagen Metman L, Fakhry M, et al. Improvement of Advanced Parkinson's Disease Manifestations with Deep Brain Stimulation of the Subthalamic Nucleus: a Single Institution Experience. Brain Sci. 2016;6:4. doi:10.3390/brainsci6040058

32. Rodriguez-Oroz MC, Zamarbide I, Guridi J, Palmero MR, Obeso JA. Efficacy of deep brain stimulation of the subthalamic nucleus in Parkinson's disease 4 years after surgery: double blind and open label evaluation. J Neurol Neurosurg Psychiatry. 2004;75(10):13821385. doi:10.1136/jnnp.2003.031294

33. Moro E, Lozano AM, Pollak P, et al. Long-term results of a multicenter study on subthalamic and pallidal stimulation in Parkinson's disease. Mov Disord. 2010;25(5):578-586. doi:10.1002/mds.22735

34. St George RJ, Carlson-Kuhta P, King LA, Burchiel KJ, Horak FB. Compensatory stepping in Parkinson's disease is still a problem after deep brain stimulation randomized to STN or GPi. J Neurophysiol. 2015;114(3):1417-1423. doi:10.1152/jn.01052.2014

35. Munhoz RP, Cerasa A, Okun MS. Surgical treatment of dyskinesia in Parkinson's disease. Front Neurol. 2014;5:65. doi:10.3389/ fneur.2014.00065

36. Tagliati M. Turning tables: should GPi become the preferred DBS target for Parkinson disease? Neurology. 2012;79(1):19-20. doi:10.1212/WNL.0b013e31825dce96

37. Follett KA, Weaver FM, Stern M, et al. Pallidal versus Subthalamic Deep-Brain Stimulation for Parkinson's Disease. $N$ Eng $J$ Med. 2010;362(22):2077-2091. doi:10.1056/NEJMoa0907083

38. Okun MS, Fernandez HH, Wu SS, et al. Cognition and mood in Parkinson's disease in subthalamic nucleus versus globus pallidus interna deep brain stimulation: the COMPARE trial. Ann Neurol. 2009;65(5):586-595. doi:10.1002/ana.21596

39. Odekerken VJJ, van Laar T, Staal MJ, et al. Subthalamic nucleus versus globus pallidus bilateral deep brain stimulation for advanced Parkinson's disease (NSTAPS study): a randomised controlled trial. Lancet Neurol. 2013;12(1):37-44. doi:10.1016/S1474-4422(12) 70264-8

40. Zahodne LB, Okun MS, Foote KD, et al. Greater improvement in quality of life following unilateral deep brain stimulation surgery in the globus pallidus as compared to the subthalamic nucleus. J Neurol. 2009;256(8):1321-1329. doi:10.1007/s00415-009-5121-7

41. Combs HL, Folley BS, Berry DTR, et al. Cognition and Depression Following Deep Brain Stimulation of the Subthalamic Nucleus and Globus Pallidus Pars Internus in Parkinson's Disease: a MetaAnalysis. Neuropsychol Rev. 2015;25(4):439-454. doi:10.1007/ s11065-015-9302-0

42. Skodda S. Effect of Deep Brain Stimulation on Speech Performance in Parkinson's Disease. Parkinson's Disease. 2014. doi:10.1155/ 2012/850596

43. Buhmann C, Huckhagel T, Engel K, et al. Adverse events in deep brain stimulation: a retrospective long-term analysis of neurological, psychiatric and other occurrences. PLoS One. 2017;12(7):e0178984. doi:10.1371/journal.pone.0178984

44. Troche MS, Brandimore AE, Foote KD, Okun MS. Swallowing and deep brain stimulation in Parkinson's disease: a systematic review. Parkinsonism Relat Disord. 2013;19(9):783-788. doi:10.1016/j. parkreldis.2013.05.001 
45. Troche MS, Brandimore AE, Foote KD, et al. Swallowing Outcomes Following Unilateral STN vs. GPi Surgery: a Retrospective Analysis. Dysphagia. 2014;29(4):425-431. doi:10.1007/s00455-014-9522-0

46. Blomstedt P, Stenmark Persson R, Hariz G-M, et al. Deep brain stimulation in the caudal zona incerta versus best medical treatment in patients with Parkinson's disease: a randomised blinded evaluation. J Neurol Neurosurg Psychiatry. 2018;89(7):710-716. doi:10.1136/jnnp-2017-317219

47. Mostofi A, Evans JM, Partington-Smith L, Yu K, Chen C, Silverdale MA. Outcomes from deep brain stimulation targeting subthalamic nucleus and caudal zona incerta for Parkinson's disease. Parkinson's Dis. 2019;5(1):1-7. doi:10.1038/s41531-019-0089-1

48. Little S, Tripoliti E, Beudel M, et al. Adaptive deep brain stimulation for Parkinson's disease demonstrates reduced speech side effects compared to conventional stimulation in the acute setting. J Neurol Neurosurg Psychiatry. 2016;87(12):1388-1389. doi:10.1136/jnnp2016-313518

49. Little S, Brown P. Debugging Adaptive Deep Brain Stimulation for Parkinson's Disease. Mov Disorders. 2020;35(4):555-561. doi: $10.1002 /$ mds. 27996

50. Rosin B, Slovik M, Mitelman R, et al. Closed-Loop Deep Brain Stimulation Is Superior in Ameliorating Parkinsonism. Neuron. 2011;72(2):370-384. doi:10.1016/j.neuron.2011.08.023

51. Parastarfeizabadi M, Kouzani AZ. A Miniature Dual-BiomarkerBased Sensing and Conditioning Device for Closed-Loop DBS. IEEE J Translat Eng Health Med. 2019;7:1-8. doi:10.1109/ JTEHM.2019.2937776

52. Ghasemi P, Sahraee T, Mohammadi A. Closed- and Open-loop Deep Brain Stimulation: methods, Challenges, Current and Future Aspects. J Biomed Phys Eng. 2018;8(2):209-216. doi:10.31661/jbpe.v8i2.898

53. Ghahremani A, Aron AR, Udupa K, et al. Event-related deep brain stimulation of the subthalamic nucleus affects conflict processing. Ann Neurol. 2018;84(4):515-526. doi:10.1002/ana.25312

54. Patel SR, Herrington TM, Sheth SA, et al. Intermittent subthalamic nucleus deep brain stimulation induces risk-aversive behavior in human subjects. Elife. 2018:7. doi:10.7554/eLife.36460

55. Fischer P, Chen CC, Chang Y-J, et al. Alternating Modulation of Subthalamic Nucleus Beta Oscillations during Stepping. J Neurosci. 2018;38(22):5111-5121. doi:10.1523/JNEUROSCI.3596-17.2018

56. Sharma VD, Sengupta S, Chitnis S, Amara AW. Deep Brain Stimulation and Sleep-Wake Disturbances in Parkinson Disease: a Review. Front Neurol. 2018;9:697. doi:10.3389/fneur.2018.00697

57. Timmermann L, Wojtecki L, Gross J, et al. Ten-Hertz stimulation of subthalamic nucleus deteriorates motor symptoms in Parkinson's disease. Mov Disord. 2004;19(11):1328-1333. doi:10.1002/ mds.20198

58. Eusebio A, Chen CC, Lu CS, et al. Effects of low-frequency stimulation of the subthalamic nucleus on movement in Parkinson's disease. Exp Neurol. 2008;209(1):125-130. doi:10.1016/j. expneurol.2007.09.007

59. Phibbs FT, Arbogast PG, Davis TL. $60 \mathrm{~Hz}$ frequency effect on gait in Parkinson's disease with subthalamic nucleus deep brain stimulation. Neuromodulation. 2014;17(8):717-720. doi:10.1111/ner.12131

60. Steigerwald F, Müller L, Johannes S, Matthies C, Volkmann J. Directional deep brain stimulation of the subthalamic nucleus: a pilot study using a novel neurostimulation device. Mov Disord. 2016;31(8):1240-1243. doi:10.1002/mds.26669

61. Timmermann L, Jain R, Chen L, et al. Multiple-source current steering in subthalamic nucleus deep brain stimulation for Parkinson's disease (the VANTAGE study): a non-randomised, prospective, multicentre, open-label study. Lancet Neurol. 2015;14(7):693-701. doi:10.1016/S1474-4422(15)00087-3

62. Ho AL, Ali R, Connolly ID, et al. Awake versus asleep deep brain stimulation for Parkinson's disease: a critical comparison and metaanalysis. J Neurol Neurosurg Psychiatry. 2018;89(7):687-691. doi:10.1136/jnnp-2016-314500
63. Hacker ML, Turchan M, Heusinkveld LE, et al. Deep brain stimulation in early-stage Parkinson disease: five-year outcomes. Neurology. 2020;95(4):e393-e401. doi:10.1212/WNL.0000000000009946

64. Hariz MI. Complications of deep brain stimulation surgery. Mov Disord. 2002;17(Suppl 3):S162-166. doi:10.1002/mds.10159

65. Blomstedt P, Hariz MI. Hardware-related complications of deep brain stimulation: a ten year experience. Acta Neurochir. 2005;147 (10):1061-1064. doi:10.1007/s00701-005-0576-5

66. Volkmann J, Albanese A, Kulisevsky J, et al. Long-term effects of pallidal or subthalamic deep brain stimulation on quality of life in Parkinson's disease. Mov Disord. 2009;24(8):1154-1161. doi: $10.1002 / \mathrm{mds} .22496$

67. Hell F, Palleis C, Mehrkens JH, Koeglsperger T. Deep Brain Stimulation Programming 2.0: future Perspectives for Target Identification and Adaptive Closed Loop Stimulation. Front Neurol. 2019;10. doi:10.3389/fneur.2019.00314

68. LeMoyne R, Mastroianni T, McCandless C, Currivan C, Whiting D, Tomycz N. Implementation of a Smartphone as a Wearable and Wireless Accelerometer and Gyroscope Platform for Ascertaining Deep Brain Stimulation Treatment Efficacy of Parkinson's Disease through Machine Learning Classification. Adv Parkinson's Dis. 2018;7(2):19-30. doi:10.4236/apd.2018.72003

69. Goetz CG, Tilley BC, Shaftman SR, et al. Movement Disorder Society-sponsored revision of the Unified Parkinson's Disease Rating Scale (MDS-UPDRS): scale presentation and clinimetric testing results. Mov Disorders. 2008;23(15):2129-2170. doi:10.1002/ mds. 22340

70. Volkmann J, Allert N, Voges J, Weiss PH, Freund HJ, Sturm V. Safety and efficacy of pallidal or subthalamic nucleus stimulation in advanced PD. Neurology. 2001;56(4):548-551. doi:10.1212/ wnl.56.4.548

71. Obeso JA, Olanow CW, Rodriguez-Oroz MC, Krack P, Kumar R, Lang AE. Deep-brain stimulation of the subthalamic nucleus or the pars interna of the globus pallidus in Parkinson's disease. $N$ Engl $J$ Med. 2001;345(13):956-963. doi:10.1056/NEJMoa000827

72. Lyons KE, Wilkinson SB, Tröster AI, Pahwa R. Long-term efficacy of globus pallidus stimulation for the treatment of Parkinson's disease. Stereotact Funct Neurosurg. 2002;79(3-4):214-220. doi:10.1159/000070834

73. Kumar R, Lang AE, Rodriguez-Oroz MC, et al. Deep brain stimulation of the globus pallidus pars interna in advanced Parkinson's disease. Neurology. 2000;55(12 Suppl 6):S34-39.

74. Lu G, Luo L, Liu M, et al. Outcomes and Adverse Effects of Deep Brain Stimulation on the Ventral Intermediate Nucleus in Patients with Essential Tremor. Neural Plast. 2015. doi:10.1155/2020/ 2486065

75. Akram H, Dayal V, Mahlknecht P, et al. Connectivity derived thalamic segmentation in deep brain stimulation for tremor. NeuroImage. 2018;18:130-142. doi:10.1016/j.nicl.2018.01.008

76. Wadhwa A, Schaefer S, Gerrard J, Deeb W, Okun MS, Patel A. Deep brain stimulation target selection in co-morbid essential tremor and Parkinson's disease. Tremor Other Hyperkinetic Movements. 2020;10:17. doi:10.5334/tohm.62

77. Cury RG, Fraix V, Castrioto A, et al. Thalamic deep brain stimulation for tremor in Parkinson disease, essential tremor, and dystonia. Neurology. 2017;89(13):1416-1423. doi:10.1212/WNL.0000000000004295

78. Thevathasan W, Debu B, Aziz T, et al. Pedunculopontine nucleus deep brain stimulation in Parkinson's disease: a clinical review. Mov Disorders. 2018;33(1):10-20. doi:10.1002/mds.27098

79. Plaha P, Gill SS. Bilateral deep brain stimulation of the pedunculopontine nucleus for Parkinson's disease. Neuroreport. 2005;16 (17):1883-1887. doi:10.1097/01.wnr.0000187637.20771.a0

80. Stefani A, Lozano AM, Peppe A, et al. Bilateral deep brain stimulation of the pedunculopontine and subthalamic nuclei in severe Parkinson's disease. Brain. 2007;130(Pt 6):1596-1607. doi:10.1093/ brain/awl346 
81. Pierantozzi M, Palmieri MG, Galati S, et al. Pedunculopontine nucleus deep brain stimulation changes spinal cord excitability in Parkinson's disease patients. J Neural Transm. 2008;115(5):731735. doi:10.1007/s00702-007-0001-8
82. Kitagawa M, Murata J, Uesugi H, et al. Two-year follow-up of chronic stimulation of the posterior subthalamic white matter for tremor-dominant Parkinson's disease. Neurosurgery. 2005;56 (2):281-289. doi:10.1227/01.neu.0000148167.49105.a3

\section{Publish your work in this journal}

Research and Reviews in Parkinsonism is an online, open access, peer-reviewed journal. The journal publishes review articles, historical reviews, original research articles, case reports, letters to the editor, clinical teaching cases, neuroradiology highlights, neuropathology highlights, neuropsychiatry highlights, autobiographies, conference proceedings, abstracts and book reviews. The manuscript management system is completely online and includes a very quick and fair peer-review system, which is all easy to use. Visit

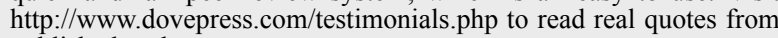
published authors. 